\title{
Data Modeling for E-Voting System Using Smart Card based E-Governance System
}

\author{
Rupali Khatun \\ Dept. Of Comp. Application, School of Engineering \& Technology \\ Amity University, Kolkata 700135, India \\ Email: rupali.khatun@live.com \\ Tania Bandopadhyay \\ Dept. Of Comp. Sc. \& Engg., School of Engineering \& Technology \\ Amity University, Kolkata 700135, India \\ Email: bandopadhyay.tania@yahoo.com \\ Dr. Abhishek Roy \\ Dept. Of Comp. Sc. \& Engg., School of Engineering \& Technology \\ Amity University, Kolkata 700135, India \\ Email: dr.aroy@yahoo.com
}

\begin{abstract}
For a developing country like India, maintaining an efficient administration within affordable budget is a big challenge. The application of Information and Communication Technology (ICT) based EGovernance can facilitate the administration in much efficient and cost effective manner compared to the traditional method of administration. Since an efficient administration is dependent on the collection of opinion of its participants (i.e the voters), flawless voting mechanism becomes the primary pillar of governance. But in the present days of busyness, many people stay away from their voting constituency due to various compulsions, thereby giving rise to number of uncast votes to a significant level. In order to solve this problem, in this paper authors have extended the concept of multifaceted smart card oriented E-Governance system to propose bio-metric authentication based E-Voting system, where Bluetooth fingerprint scanner will be paired with the voter's smart phone to implement the proposed concept. This propose system will use a mobile application to input user identification number using the Multipurpose Electronic Card (MEC) based EGovernance system. In case of successful authentication, the voter will be allowed to caste the original vote, else it will be barred. Hence, this approach will prevent the malicious tendency of proxy voting using advanced authentication system. Since this proposed E-Voting system have to handle huge data traffic during its implementation, its database should be designed at first to reduce data redundancy and inconsistency as much as possible. Hence, in this paper, authors have designed its database system using Data Flow Diagram (DFD), Entity Relationship Diagram (ERD) to demonstrate the relationship between its primary entities and tables.
\end{abstract}

Index Terms-E-Governance, E-Voting, Database Modeling, Smart Card.

\section{INTRODUCTION}

For a developing country like India, maintaining an efficient administration within affordable budget is a big challenge. The application of Information and Communication Technology (ICT) based E-Governance can facilitate the administration in much efficient and cost effective manner compared to over traditional method of administration. Since an efficient administration is dependent on the collection of opinion of its participants (i.e the voters), flawless voting mechanism becomes the primary pillar of governance. But in the present days of busyness, many people stay away from their voting constituency due to various compulsions, thereby giving rise to the number of uncast votes to a significant level. This problem can be sort out by the use of advanced communication technologies and authentication mechanisms. In order to solve this problem, in this paper authors have extended the concept of multifaceted smart card oriented E-Governance system to propose bio-metric authentication based E-Voting system, where Bluetooth fingerprint scanner will be paired with the voter's smart phone to implement the proposed concept. This propose system will use a mobile application to input user identification number using the Multipurpose Electronic Card (MEC) based EGovernance system. In case of successful authentication, voter can view the candidate name, political party affiliation, political party symbol, personal information of the candidate like educational records, financial records, criminal records (if any), etc. w.r.t. the constituency of that specific voter. Based on these information, voter will be able to choose the appropriate candidate from the respective constituency though its voting right. Furthermore, this approach will strengthen our administration by preventing the infiltration of inappropriate candidates like criminals, political 
hooligans, etc. within our governance. As it is well understood that the proposed E-Voting system will handle huge load of data traffic, in this paper the authors have designed the database of the proposed system using Data Flow Diagram (DFD), Entity Relationship Diagram (ERD) to establish the relationship between its entities and tables.

For better understanding of the propose system, background of smart card based E-Governance system are explained in section II and section III respectively. The database design of our proposed E-Voting system are explained through Data Flow Diagram, Entity Relationship Diagram (ERD), etc. in section IV of this paper. Section V have concluded this paper thereby exploring the future scope of this proposed E-Voting system..

\section{RELATED WORKS}

Electronic Governance (i.e. E-Governance) is the electronic mechanism used for deployment of administration by the state-owned agencies under its jurisdiction using Information and Communication Technology (ICT). As E-Governance makes communication faster than its conventional counterpart, it reduces the huge budget expenses of the government in every aspect, like stationary, man power, operational overhead, etc. Hence as a whole, this electronic message communication becomes very much efficient and transparent in terms of resource investment and its corresponding output generation. It also makes the Government very much accountable to its Citizen in terms of accurate delivery of services. However, to defend the unauthorized access of electronic message communication between the Government and Citizen, EGovernance must implement strict authentication system, which is explained further in this paper.

\section{FOUNDATION OF RESEARCH WORK}

With the objective to provide smart, secured and an efficient E-Governance system, a Citizen centric multifaceted smart card based E-Governance [1-16,19-23] system was already proposed earlier, which is the basic foundation of our proposed E-Voting system.

The said Citizen centric E-Governance system uses a smart card (i.e. Multipurpose Electronic Card [MEC]) as the primary interface between Citizen and Government during delivery of electronic services in one-to-one communication, whose conceptual diagram during Citizen-to-Government (C2G) type of transactions is shown in Figure - 1.

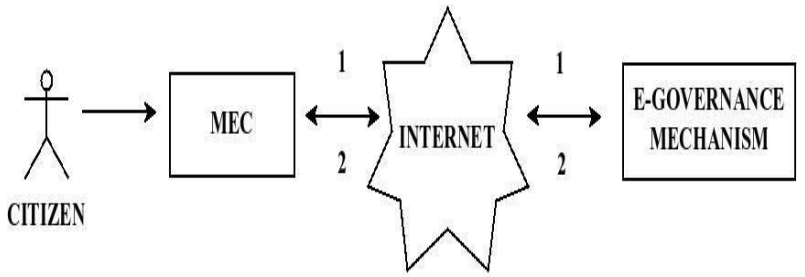

\section{1 : SERVICE REQIEST 2 : SERVICE RESPONSE}

Fig.1. Conceptual Diagram of the smart card based E-Governance system.

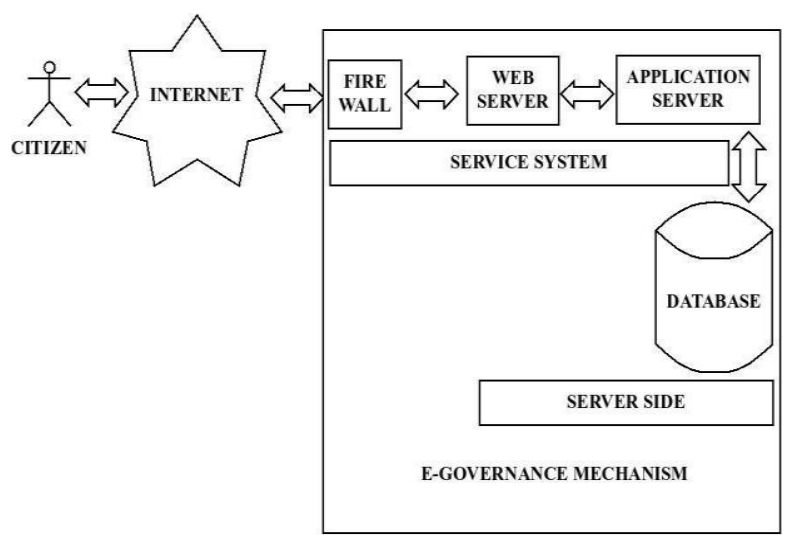

Fig.2. Architecture of the proposed E-Governance model

The architecture of this E-Governance system during Citizen-to-Government (C2G) type of transaction is shown in Figure - 2, which is further described below -

1. The Citizen initiate E-Governance transaction using Multipurpose Electronic Card (MEC).

2. Since Multipurpose Electronic Card (MEC) is the primary interface between Citizen and Government in this E-Governance system, it will further communicate with Government to convey the service requested by its user i.e. Citizen.

3. Our E-Governance mechanism contain the following components.

a. Firewall- It prevent the unauthorized access from any private network including spamware, malware and other malicious elements.

b. Web server- After the data passes through the firewall, it enters the Web Server of the electronic mechanism. The exchange of information between Citizen and Government is performed here.

c. Application server - In this phase the data interact with the Application Server of the system.

d. Database - The final data set of EGovernance transaction is stored in this database for future use. 
4. The Service System of the our E-Governance mechanism consists of Firewall, Web Server and the Application Server.

5. The Server side consists of Web Server, Application Server and Database.

The entire E-Governance transaction proceeds in bidirectional manner, which includes request from the Citizen and its corresponding response from the Government.

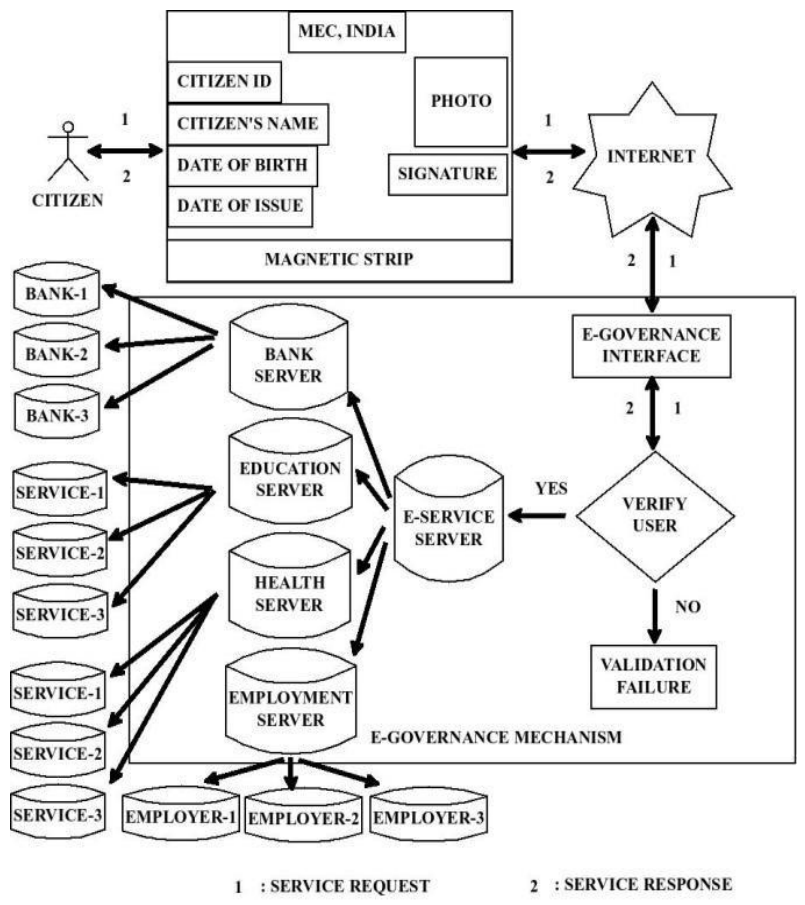

Fig.3. Schematic diagram of proposed smart card based E- Governance mechanism during $\mathrm{C} 2 \mathrm{G}$ type of transaction.

Figure - 3 shows the enhanced schematic diagram of our E-Governance system, where Citizen enjoys various electronic services like banking services, educational services, health services, employment services, etc using Multipurpose Electronic Card (MEC). The efficiency of this system is highly dependent on the implementation of strict authentication mechanism installed within it, without which this electronic system will be totally useless. As an extension to the delivery of electronic services to the Citizen using the said smart card based EGovernance system, authors have proposed an E-Voting system, which is discussed next in this paper.

\section{Proposed SMart CARd BASEd E-Voting System}

Figure - 4 shows our proposed E-Voting system using Multipurpose Electronic Card (MEC) during Citizen-toGovernment (C2G) type of E-Governance transaction.

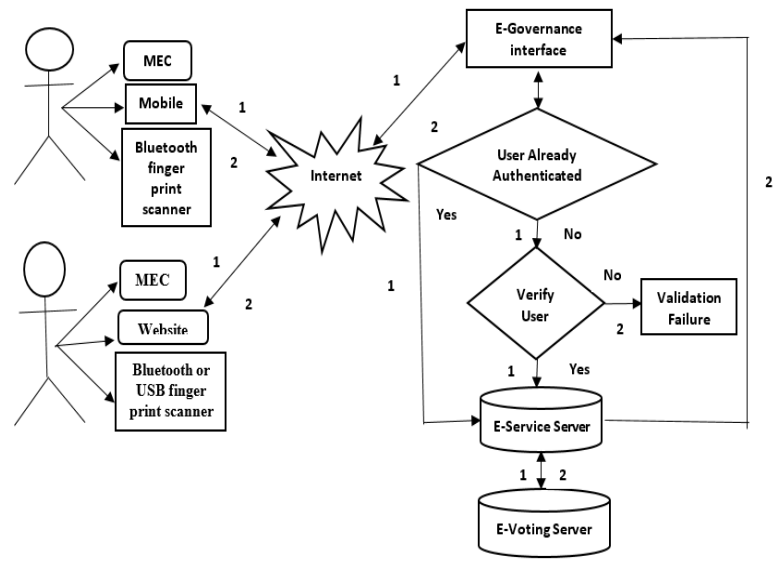

Fig.4. Proposed E-Voting system using Multipurpose Electronic Card (MEC).

The proposed Biometric $[\mathbf{1 7 , 1 8}]$ authentication based E-Voting system may be described as below -

\section{Activities on Citizen side:}

Step - 1: Citizen initiates the voting process using Multipurpose Electronic Card (MEC), biometric (i.e. finger print) scan and/or mobile application / website login. This process provides two stage security at the initial stage -

a. Multipurpose Electronic Card (MEC) unique identification number verification - In India though Aadhaar Card also claims to provide unique identification number to Citizen, however itself being a paper based (i.e. hard copy) identity instrument, Aadhaar Card does not provide any option for smart electronic transactions for its original user.

b. Biometric (i.e. finger print) authentication - Using this biometric verification system, Citizen can safely cast its own vote, thereby bypassing any possibilities of proxy voting. This biometric parameter of the Citizen i.e. Voter is either transmitted to the Government using a mobile application or laptop paired with biometric (i.e. finger print) scanner of the Voter.

As Figure - 4 denotes Service Request using path - 1 and Service Response using path - 2, Citizen sends its message (i.e. request to grant voting right) to Government through path -1 .

\section{Activities on Government side:}

Step - 2: E-Governance interface receives the message send by Citizen i.e. Voter and passes through two step verification, one for Multipurpose Electronic Card (MEC) and other for bio-metric parameter of the user. 
Step - 2.1: In case of successful verification for both the steps, Service Request of the Citizen is processed further.

Step - 2.2: In case of unsuccessful verification at any of the steps, Service Request is aborted and Negative Acknowledgment (NAC) is send to the Citizen i.e Voter through path -2 .

Step - 3: Only in case of successful verification of Citizen, Service Request is passed to E-Service Server, mainly to record the vital parameters of the Service Request. The Service Request will be processed further to access the E-Voting Server only if the Date of Election and Voting Constituency of the user matches (which can be obtained through Multipurpose Electronic Card [MEC]) as per the records stored in database. In case of mismatch, E-Service Server will report database inconsistency to E-Governance interface, which will finally send Negative Acknowledgment (NAC) to the Citizen through path - 2. This step will actively defend the malicious approach of proxy voting.

Step - 4: Citizen i.e. Voter can reach to this step after successful completion of all type of verification system, where the details of contesting candidate, political party name, political party symbol, educational background of the candidate, financial background (i.e. professional details, etc), criminal background, if any, will be displayed to the Voter. Based on these information and good sense of judgment, Voter can cast vote to its favorite candidate, which will successfully conclude our proposed E-Voting system using Citizen centric multifaceted smart card .

Since our proposed E-Voting system have to manage huge load of data, in the following section we have explained its database using Data Flow Diagram, Entity Relationship Diagram (ERD) to demonstrate its primary participants and their inter - table relationships.

Data Flow Diagram (DFD) -

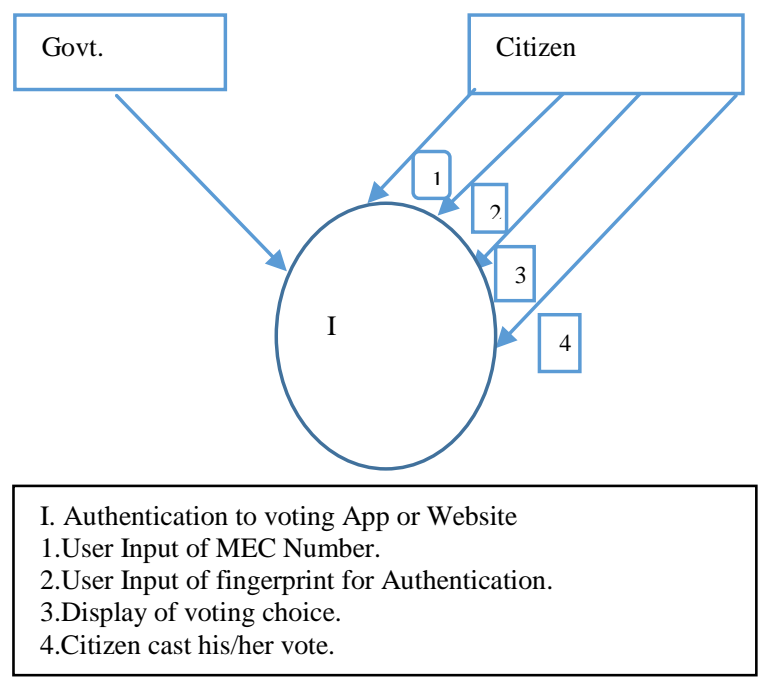

Fig.5. Context Level DFD of proposed E-Voting system.

Figure- 5. shows that the Citizen provides its Multipurpose Electronic Card (MEC) and finger print scan respectively for verification of its request for voting. After successful verification of the Citizen, the voting choices are displayed for completion of electronic voting process. However, to complete this electronic process, Government must provide necessary support to the Citizen.using its multifaceted smart card (i.e. Multipurpose Electronic Card) based E-Governance system.

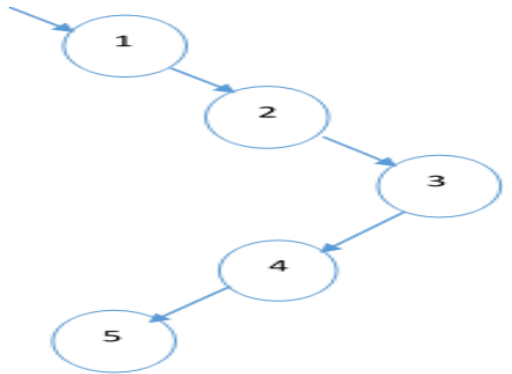
1. Citizen enters MEC number
2. Citizen provides fingerprint
3. Verification of MEC number \& fingerprint for voting.
4. Display of voting choices.
5. Citizen cast his vote.

Fig.6. Level 1 DFD of proposed E-Voting system.

Figure 6. shows the sequential usage of Multipurpose Electronic Card (MEC) and finger print scan as verification parameters for casting of vote using our proposed electronic voting system.

To develop an efficient E-Voting system, its primary entities should be identified accurately, which are shown in Figure - 7.
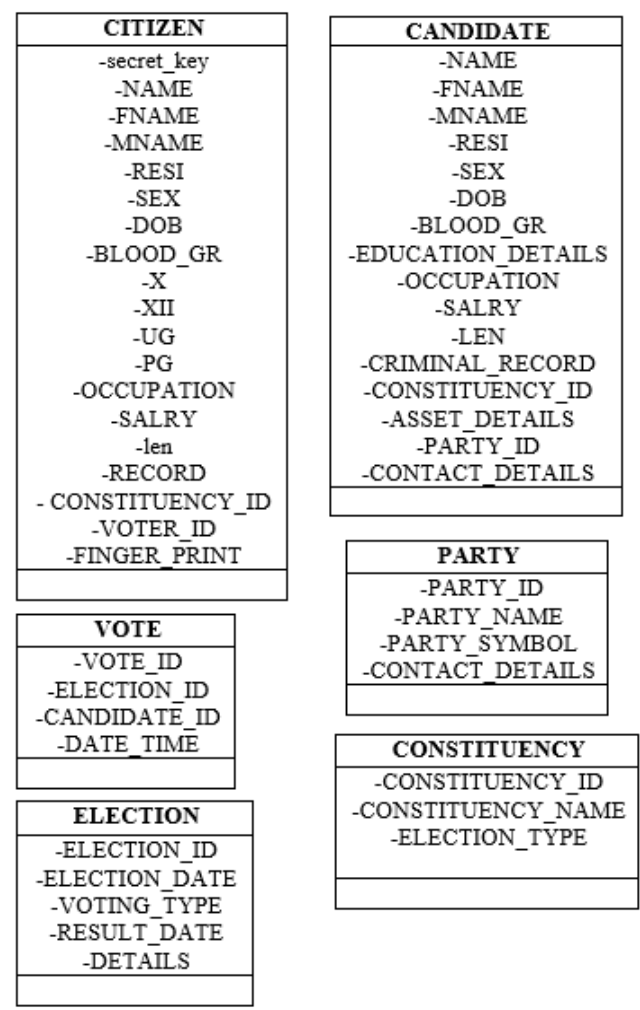

Fig.7. Primary entities of proposed E-Voting system. 
Figure - 7. shows the respective attributes of the primary entities of E-Voting system in a self explanatory manner. To represent the data required for this E-Voting subsystem, the above prime entities can be used. Citizen entity holds the details of the citizen, which is also a part of the original proposed model of the MEC. This entity contains a field called constituency ID, which is a reference of constituency entity. In case of user login, authentication is done based on this Citizen entity. After that, the details regarding the election are shown by identifying the constituency of the voter using this constituency ID reference. The election type attribute contains the information about type of election for this constituency like, Assembly, Municipal etc. This is arranged to demarcate the polling zone. Election entity contains information about each election. It contains election date, type, result date and other details. Party entity is used to store information about each party. Name of the party, election symbol, contact details are stored in this entity. Candidate entity contains information regarding each candidate which includes his/her general details, details of asset, his/her criminal records, if any, etc.

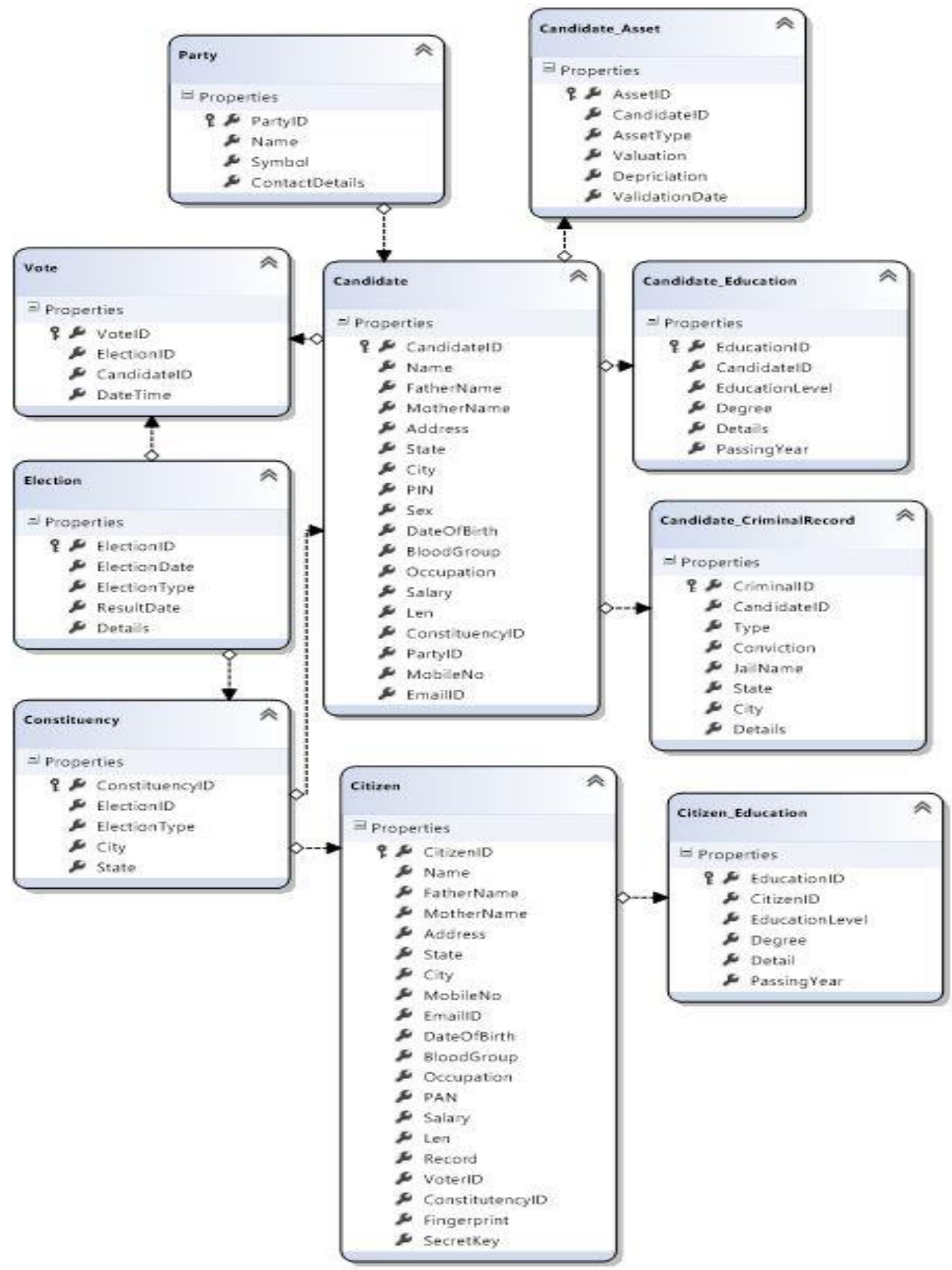

Fig.8. Inter - table relationship of our E-Voting system. 
All these information will be shown to the voter before casting of vote. This will help in complete transparency. Candidate entity contains party ID which is used to identify the party to which the candidate belongs. For any independent contestant, a party tuple will be created to record the symbol so as to denote the candidate as an independent contestant. Candidate entity also contains constituency ID which is a reference to Constituency entity, helps to identify for which constituency the candidate is contesting from and election ID which is a reference to Election entity, used to identify for which election this candidate is contesting. Vote entity is used to store every vote casted by citizen. Election ID is a reference to election entity to understand that this vote is cast for which election and candidate ID is used to identify the candidate receiving the vote. No information about the voter is stored for anonymity. Lastly, CitizenVoteCast (shown in Figure - 9.) entity will store the information regarding - if a voter has cast his vote in any election or not to avoid repeated votes cast by same individual.

However, the inter - table relationship of our proposed E-Voting system is shown in Figure - 8.

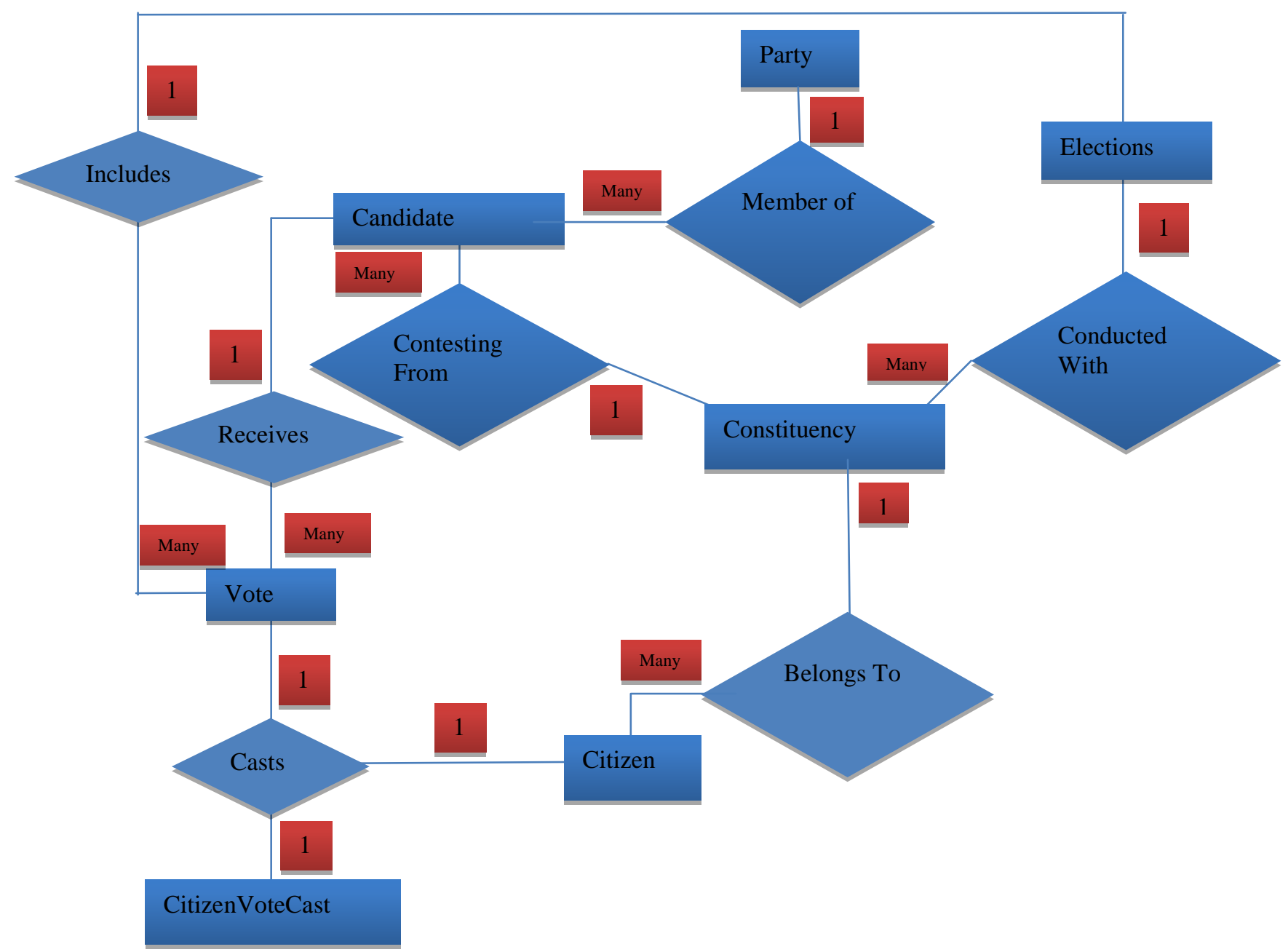

Fig.9. Entity Relationship Diagram of our E-Voting system.

\section{Data Modeling -}

Since this proposed E-Voting system will execute electronic voting system for every citizen, it should be highly consistent to handle bulk load of data. For secure handling of these classified information, Data Modeling using Entity Relationship Diagram (ERD) is shown in Fig. 9, whose parameters have been already explained above.

ERD may be further described as below -

1. MEMBER OF: - Many Candidates are member of a single party. Every candidate is a member of any party. Those who are contesting without any party, for them also a entry for them is also made in party table as party table will supply the candidates with their voting symbol.

2. CONTESTING FROM: - Many candidates contests from a single constituency. Every constituencies has multiple candidates who contest among themselves to win that particular constituency.

3. BELONGS TO: - Many citizen belongs to a single constituency. During any vote, every citizen is put into constituencies based on their home address. 
4. CONDUCTED WITH: - Every Election like Assembly Election, Municipality Election etc. are conducted with many constituencies. These constituencies may vary based on the election type, like the constituencies constructed for assembly pole is not same as municipality pole as during municipality elections are conducted for each ward, then individual wards are treated as constituency.

5. CASTS: - Every individual citizen Casts one vote each in any given election. Whether a citizen casts its vote or not is tracked by CitizenVoteCast entity.

6. INCLUDES: - Every election includes many votes from individual citizens.

7. RECEIVES: - Every candidate receives multiple votes from citizens in any given election.

Figure - 9. shows the relationship among the entities in a simpler form mainly for better understanding of the concept, which may get modified during real world implementation using distributed database system.

\section{CONCLUSION}

Our proposed E-Voting subsystem will help many voters to cast their vote hassle free with the help of advanced Information and Communication Technology. To make this system highly secure and successful, Government have to take major part in the entire process by providing necessary logistics support to the Citizen. On the other hand, by providing these logistics support Government can keep a track of its Citizen during the election, which will help to detect and subsequent cancellation of proxy votes. Since the data modeling of our proposed E-Voting system is in its initial stage, its database connection and simulation will help it to improve further. Our proposed system may be enhanced to its corresponding cloud model, where cyrptographic security protocols will be embedded to handle the sensitive database of entire election in a distributed manner thereby keeping checks and bounds for database failures.

\section{REFERENCES}

[1] Roy A, Information Security in E-Governance : A case study based analysis, International Journal of Research in Engineering \& Advanced Technology (IJREAT), 2015, 3(1): 168-173, ISSN 2320-8791.

[2] Roy A, Synopsis on Information Security in EGovernance using Cryptography, International Journal of Advanced Technology in Engineering and Science (IJATES), 2014, 02(01): 432-445, ISSN (Online) 23487550.

[3] Roy A, Karforma S, Authentication of user in EGovernance : A Digital Certificate based approach, International Journal of Scientific Research and Management (IJSRM), 2014, 2(8): 1212-1221, ISSN 2321-3418.

[4] Roy A, Karforma S, E-Governance To E-Commerce : A Smart Transition, International Journal of Emerging Research in Management and Technology (IJERMT), 2014, 3(7): 82-86, ISSN 2278-9359.
[5] Roy A, Karforma S, E-Governance To E-Health : A Smart Road Map For Society, The International Journal of Science and Technoledge (The IJST), 2014, 2(7): 217-221, ISSN 2321-919X.

[6] Roy A, Karforma S, Data Modeling of a multifaceted electronic card based secure E-Governance system, Chapter No: 12 of Book Emerging Mobile and Web 2.0 Technologies for Connected E-Government by Dr. Zaigham Mahmood, University of Derby, United Kingdom (UK), Published by: IGI Global, USA, Pp: 280299, DOI: 10.4018/978-1-4666-6082-3.ch012

[7] Roy A, Karforma S, Stream cipher based user authentication technique in E-Governance transactions, International Society of Thesis Publication Journal of Research in Electrical and Electronics Engineering (ISTPJREEE), 2014, 3(3): 31-37, ISSN 2321-2667.

[8] Roy A, Karforma S, A Study on implementation of security in E-Governance using cryptography, International Journal of Advanced Research in Computer Science and Software Engineering (IJARCSSE), 2014, 4(4): 652-659, Print ISSN 22776451 Online ISSN 2277 $128 \mathrm{X}$.

[9] Roy A, Karforma S, Coupling and cohesion analysis for implementation of authentication in E-Governance, ACEEE Conference Proceedings Series 02, Fourth International Joint Conference - Advances in Engineering and Technology (AET) 2013, 2013 (Elsevier), Pp: 544554, Organized by: The Association of Computer Electronics and Electrical Engineer (ACEEE), The Association of Mechanical and Aeronautical Engineers (AMAE), The Association of Civil and Environmental Engineers (ACEE), Sponsored by : Indian Society for Technical Education (ISTE), NCR, INDIA. ISBN 978-935107-193-8.

[10] Roy A, Karforma S, Object oriented metrics analysis for implementation of authentication in smart card based EGovernance mechanism, Researchers World - Journal of Arts, Science and Commerce, 2013, IV(Issue - 4(2)): 103 - 109 Print ISSN 2231-4172 Online ISSN 2229-4686.

[11] Sarkar S, Roy A, Survey on Biometric applications for implementation of authentication in smart Governance, Researchers World - Journal of Arts, Science and Commerce, 2013, IV(Issue - 4(1)): 103 - 114, Print ISSN 2231-4172 Online ISSN 2229-4686.

[12] Roy A, Karforma S, Banik S, Implementation of authentication in E-Governance - An UML Based Approach, Book published by LAP Lambert Academic Publishing 20131 Ed, Germany, ISBN 978-3-659-413100

[13] Roy A, Karforma S, UML based modeling of ECDSA for secured and smart E-Governance system, Computer Science \& Information Technology (CS \& IT - CSCP 2013), Proceedings of National Conference on Advancement of Computing in Engineering Research (ACER13) organized by Global Institute of Management and Technology, 2013, Pp: 207 - 222, ISSN 2231 - 5403, ISBN 978-1-921987-11-3, DOI: 10.5121/csit.2013.3219

[14] Roy A, Karforma S, Object Oriented approach of Digital certificate based E-Governance mechanism, ACEEE Conference Proceedings Series 03, International Conference on IPC\&ITEeL ACT\&CIIT CENT\&CSPE 2012 Proceedings, 2012 (Elsevier), Pp: 380-386, Organized by: The Association of Computer Electronics and Electrical Engineer (ACEEE), Chennai, INDIA. ISBN 978-93-5107-194-5. 
[15] Roy A, Karforma S, A Survey on digital signatures and its applications, Journal of Computer and Information Technology, 2012, 03(1 \& 2): 45-69, ISSN 2229-3531.

[16] Hoda A, Roy A, Karforma S, Application of ECDSA for security of transaction in E-Governance, Proceedings of Second National Conference on Computing and Systems 2012 (NaCCS - 2012) organized by the Department of Computer Science, The University of Burdwan, 2012, 1st Edition - 2012, Pp: 281-286, ISBN 978-93-80813-18-9.

[17] Sarkar S, Roy A, A Study on Biometric based Authentication, Proceedings of Second National Conference on Computing and Systems - 2012 (NaCCS 2012) organized by the Department of Computer Science, The University of Burdwan, 2012, 1st Edition - 2012, Pp: 263-268, ISBN 978-93-80813-18-9.

[18] Roy A, Sarkar S, Mukherjee J, Mukherjee A, Biometrics as an authentication technique in E-Governance security, Proceedings of UGC sponsored National Conference on "Research And Higher Education In Computer Science And Information Technology, RHECSIT-2012" organized by the Department of Computer Science, Sammilani Mahavidyalaya in collaboration with Department of Computer Science and Engineering, University of Calcutta, 2012, Vol: 1, Pp:153-160, ISBN 978-81923820-0-5.

[19] Roy A, Karforma S, Risk and Remedies of E-Governance Systems, Oriental Journal of Computer Science \& Technology (OJCST), 2011,04(02): 329-339. ISSN 09746471.

[20] Roy A, Banik S, Karforma S, Object Oriented Modelling of RSA Digital Signature in E-Governance Security, International Journal of Computer Engineering and Information Technology (IJCEIT), Summer Edition 2011, Vol 26 Issue No. 01, Pp: 24-33, ISSN 0974-2034.

[21] Roy A, Karforma S, A Survey on E-Governance Security, International Journal of Computer Engineering and Computer Applications (IJCECA). Fall Edition 2011, Vol 08 Issue No. 01, Pp: 50-62, ISSN 0974-4983.

[22] Roy A, Banik S, Karforma S, Pattanayak J, Object Oriented Modeling of IDEA for E-Governance Security, Proceedings of International Conference on Computing and Systems 2010 (ICCS 2010), 2010, Pp: 263-269, Organized by: Department of Computer Science, The
University of Burdwan, West Bengal, INDIA. ISBN $93-$ 80813-01-5.

[23] Sur C, Roy A, Banik S, A Study of the State of EGovernance in India, Proceedings of National Conference on Computing and Systems 2010 (NACCS 2010), 2010, Pp: a-h, Organized by : Department of Computer Science, The University of Burdwan, West Bengal, INDIA. ISBN 8190-77417-4.

\section{Authors' Profiles}

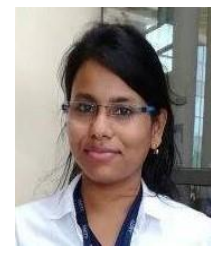

Ms. Rupali Khatun, She is a post-graduate student for degree in Computer Application (i.e. MCA) in Amity University, Kolkata. She is currently having her research work under the supervision of Dr. Abhishek Roy. Her research interest includes: cryptography, information security, steganography.

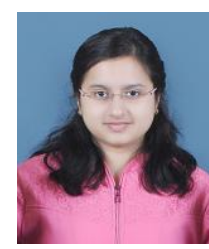

Ms. Tania Bandopadhyay, She is an undergraduate student for degree in Computer Science \& Engineering (i.e. B.Tech Computer Science \& Engineering) in Amity University, Kolkata. She is currently having her research exposure under the supervision of Dr. Abhishek Roy. Her research interest includes: cryptography, information security, e-governance.

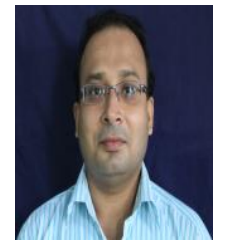

Dr. Abhishek Roy, Author is an Assistant Professor of School of Engineering \& Technology at Amity University, Kolkata. He is also the Life Member of Cryptology Research Society of India, Indian Statistical Institute, Kolkata. His research interest includes: Cyber Security, E-Governance.

For further details please contact at -

Email: dr.aroy@yahoo.com; dr.aroy@gmx.com

URL: https://sites.google.com/site/diaryofaroy

How to cite this paper: Rupali Khatun, Tania Bandopadhyay, Abhishek Roy,"Data Modeling for E-Voting System Using Smart Card based E-Governance System", International Journal of Information Engineering and Electronic Business(IJIEEB), Vol.9, No.2, pp.45-52, 2017. DOI: 10.5815/ijieeb.2017.02.06 